\title{
Application Prospect Analysis of Energy-saving Sunlight Greenhouse with Underground Drip Irrigation and Heat
}

\author{
Dejie Zhao ${ }^{1, a}$ \\ ${ }^{1}$ North China Electric Power University, Baoding, 071000, China \\ a877040094@qq.com
}

Keywords: Energy - saving sunlight greenhouse, underground heat storage, application prospect.

\begin{abstract}
In order to create the best artificial climate suitable for plant growth and to meet the requirements for energy saving, environmental protection and economic operating costs, this article designs an energy-saving sunlight greenhouse with underground drip irrigation and heat. Combining the greenhouse underground heat storage system with warm water irrigation technology can effectively realizes the goal of collecting solar energy during the day and releasing it at night. After the actual calculation, a heating season can save cool for $5428 \mathrm{~kg} / 500 \mathrm{~m}^{2}$ and reduce carbon dioxide emissions about $13533 \mathrm{~kg} / 500 \mathrm{~m}^{2}$. From the perspective of energy saving and environmental protection, energy-saving sunlight greenhouse with underground drip irrigation and heat will create an effective way for greenhouse warming in winter.
\end{abstract}

\section{Background and Significance}

Nowadays, non-heating greenhouse is widely used in China. However, this system can't make vegetables grow safely during the winter due to the low temperature. Therefore, some greenhouses use coal as energy supply, but it will lead to energy consumption, high cost and low utilization. In summary, current greenhouse is either too cold in winter, or too polluted for environment. Meanwhile, traditional greenhouse has low utilization for light, temperature and energy, which doesn't meet the requirements for agricultural sustainable development. In order to create the best suitable climate for plant growth and meet the requirements for energy saving, environmental protection and economic operating costs, researching how to make full use of solar energy for greenhouse production has attracted the world's attention.

Thus, we develop an energy-saving sunlight greenhouse with underground drip irrigation and heat. This system effectively collects solar energy during the day and releases heat at night. It can meet the requirement for crop growth in winter without artificial warming, which effectively improves the utilization of greenhouse energy and achieves energy conservation.

\section{Working Principle}

When the conditions of light and temperature are good, collect solar energy to heat water in the collector. Then inject the hot water into the storage box. When the temperature is low, inject the hot water in he storage box into the radiating pipe underground. Utilize the water's heat dissipation to improve the shallow surface temperature of the greenhouse, and it'll meet the root temperature requirements. When the water temperature drops, use water-pump to siphon cold water into the cold water tank and inject hot water into the radiating pipe. Thereby the system realizes cycle control. Irrigation system uses subsurface irrigation system and the water used is mixed by hot water and tap water. Therefore, it achieves warm drip irrigation. Meanwhile, we establish the U-saving insulation material with a small hole to reduce water loss and heat loss.

\section{Innovation and application prospects}

\section{Innovation.}

The system creatively combines the greenhouse underground heat storage system with warm water irrigation technology. From the perspective of energy saving and environmental protection, it 
creates an effective way for greenhouse warming in winter.

1) Solar energy -- clean, low emissions

Traditional greenhouse uses coal as energy, which leads to huge energy consumption and pollution. However, our system uses solar energy as energy. It not only meets the requirement for crop growth in winter without artificial warming, but also has little population.

2) Underground heat storage system -- heating, nursery

Laying heat pipe underground to heat the soil can make better use of solar energy and do good to plant growth. In order to make up for the defects of solar greenhouse, the paper creatively designs underground pipeline laying way and water flow direction, and establishes the U-saving insulation material with small hole to reduce water loss and heat loss.

3) Fixed water irrigation system -- water saving, production increased

Underground fixed irrigation system can reduce water evaporation and control temperature and humidity. Water source is mixed with hot water and tap water to achieve warm water irrigation, which increases root activity and resistance of plants.

\section{Prospects.}

The system can effectively realize energy conservation and improve crop yields, and produce better social and economic benefits. As China's grim fog weather gets worse and worse, sunlight and temperature's will shrink in traditional greenhouse. However, this system can reasonably allocate solar energy resources to realize the continuous heating of greenhouses. It can be believed that with more mature solar collector technology, the system will have a broader application prospects.

\section{Theoretical Analysis}

The data were collected in experimental greenhouse of Hebei Academy of Agriculture and Forestry. The greenhouse was $50 \mathrm{~m}$ long, $9.85 \mathrm{~m}$ wide and $3.5 \mathrm{~m}$ high.

\section{Analysis of Heat Consumption in Greenhouse.}

The analysis of heat consumption in greenhouse is the basic for design energy-saving sunlight greenhouse with underground drip irrigation and heat, and is the main content of carrying out heat load budget. The calculated values are related to heat release area, building structure, materials and regional climatic conditions.

1) Heat consumption of building envelope

As long as there is temperature difference inside and outside the greenhouse, heat will pass through the envelope structure from indoor to outdoor. On the condition of stable heat transfer, heat consumption of the envelope can be calculated according to the following formula:

$$
q=k F\left(t_{n}-t_{w}\right) f_{r}
$$

After calculation, heat consumption of greenhouse building envelope are shown in Table 1.

Table 1 Heat consumption of greenhouse building envelope

\begin{tabular}{ccccc}
\hline \hline Name & $\begin{array}{c}\text { Heat transfer } \\
\text { coefficient k } \\
W /\left(m^{2} \cdot{ }^{\circ} \mathrm{C}\right)\end{array}$ & Heat dissipation area & $\begin{array}{c}\text { Indoor and outdoor } \\
\text { temperature } \\
\left(\mathrm{m}^{2}\right)\end{array}$ & Heat loss \\
& & & & $(\mathrm{KJ} / \mathrm{h})$ \\
\hline heat transfer of front wall & 1.85 & 553 & 26.58 & 97893.6 \\
heat transfer of back wall & 1.16 & 61 & 26.58 & 6770.8 \\
Wall heat transfer & 0.71 & 262 & 26.58 & 17799.9 \\
\hline \hline
\end{tabular}

2) heat consumption of cold air penetration

The cold air entered into the room by the cracks will be heated and then escape. The heat consumed by the cold air is heat consumption of cold air penetration. And it can be calculated according to the following formula: 


$$
Q_{u}=R V C_{p}\left(t_{n}-t_{w}\right)
$$

Experiments show that the base temperature in winter greenhouse is 15.58 degrees. By looking at the HVAC design manual, the outdoor ambient temperature is -11 degrees. And then we have:

$$
Q_{u}=34842.87 \mathrm{KJ} / \mathrm{h}
$$

3) Heat loss in the ground

Heat loss of conduction in the soil consists of vertical heat transfer in the vertical direction and horizontal heat transfer in the horizontal direction, of which the heat in the horizontal conduction really spread outdoors. The formula is:

After calculation, heat loss in the ground is:

$$
Q_{d}=\sum k_{d f} F\left(t_{n}-t_{w}\right)
$$

$$
Q_{d}=16846.1 \mathrm{KJ} / \mathrm{h}
$$

\section{Analysis of Solar Thermal Radiation Absorption in Greenhouse.}

The amount of solar radiation in the greenhouse varies with latitude, time and greenhouse orientation. Average monthly direct radiation total $\mathrm{G}_{\mathrm{h}}$ in the greenhouse can be calculated as follows:

$$
G_{\mathrm{h}}=\frac{\frac{1}{m} \sum_{1}^{m} \sum_{p}^{q} A_{j} G_{\alpha}}{A}
$$

In the experiment of lighting amount, we found that the proportion of solar radiation in different parts of the greenhouse is different. The light distribution characteristics of the laboratory are $59 \%$ of the light exposure to the ground, 35\% to the back wall, $6 \%$ to reach the roof . The absorption rate of soil is 0.82 , and the absorption rate of back roof is 0.71. Thus Solar Thermal Radiation Absorption in Greenhouse is:

$$
Q_{s}=2982265.4 \mathrm{KJ}
$$

\section{Energy-saving effect analysis}

1) Emission reduction

In the central region of Hebei, greenhouse heating period is from mid-November to mid-March the following year. During the 4-month heating period, a greenhouse with $500 \mathrm{~m}^{2}$ area will need $30000 \mathrm{~kg}$ coal, which not only causes pollution, but also increases investment in vegetable farmers. While using solar underground heat storage system can make the greenhouse warm without using fuel. It can not only make plants survive the winter, but also save the consumption of coal. Take the average daily cumulative radiation in January to estimate the amount of heat the system provides. The results are shown in the following table:

Table 2 Analysis results of emission reduction

\begin{tabular}{ccccc}
\hline \hline $\begin{array}{c}\text { Greenhouse area } \\
\left(\mathrm{m}^{2}\right)\end{array}$ & $\begin{array}{c}\text { The heat released } \\
\text { in one month } \\
(\mathrm{KJ} / \mathrm{month})\end{array}$ & $\begin{array}{c}\text { The heat released } \\
\text { in a heating season } \\
(\mathrm{KJ} / \mathrm{season})\end{array}$ & $\begin{array}{c}\text { Coal saving } \\
(\mathrm{kg} / \mathrm{season})\end{array}$ & $\begin{array}{c}\text { Reduced } \\
\mathrm{CO}^{2} \text { emissions } \\
(\mathrm{kg} / \mathrm{season})\end{array}$ \\
\hline 500 & $7.6 \times 10^{\wedge} 6$ & $3.8 \times 10^{\wedge} 7$ & 5428.57 & 13533.27 \\
\hline \hline
\end{tabular}

Thus, it can be concluded that using underground heat storage system can save $5428 \mathrm{~kg} / 500 \mathrm{~m}^{2}$ of standard coal in one heating season and reduce carbon dioxide emissions of about $13533 \mathrm{~kg} /$ $500 \mathrm{~m}^{2}$.

2) Water saving

Water saving equals annual water consumption of traditional greenhouse irrigation minus annual water consumption of underground drip irrigation system. The experiment measures that the 
traditional greenhouse irrigation's water consumption is $496 \mathrm{~m}^{3}$, and annual water consumption of subsurface drip irrigation system is $374 \mathrm{~m}^{3}$. Thus, the system can save water for $122 \mathrm{~m}^{3}$ in one year.

\section{References}

[1] Duangsheng Chen.Progress Research on of Building and Environment of Energy - saving Sunlight Greenhouse in China[J].Journal of Agricultural Engineering.1994.10(1):120-130

[2] Changji Zho,Songtao Wang.Several Problems in the Standardization of Greenhouse Engineering[J].Journal of Agricultural Engineering.2002.18(4):190-195

[3] Yaolin Wang.Energy-saving solar greenhouse and its sustainable development approach (c)[J].Chinese Vegetables,2000,(3):50-54

[4] Yikui Bai,Tieliang Wang.Design of Daylight Greenhouse Combustion - Ground Heat Exchange System[J],Northern Gardening, 2006,6:60-65. 